\title{
Performance and Emission Characteristics of Liquid Biofuels Cooking Stoves
}

\begin{abstract}
By Adamu Shanono ${ }^{*}$ Ibraheem Diso ${ }^{ \pm} \&$ Isa Garba
Jatropha Oil Bio Stove (JOBS) and Neem Oil Bio Stove (NOBS) that utilised blends of raw oils of Jatropha and Neem with Kerosene respectfully as fuels were designed and developed at the Bayero University Kano - Nigeria. The Water Boiling Test (WBT) version 4.2.3 and Controlled Cooking Test (CCT) version 2.0 were conducted on the Liquid Biofuels Stoves while combusting six kerosene/oil blends. Similar tests were carried out on the Butterfly Kerosene Cooking Stove with kerosene as fuel for the purpose of comparison. Results of the tests indicated that the Butterfly Stove with kerosene as fuel, and the JOBS when combusting $10 \%$ and 20\% Jatropha oil concentrations in the blends produced the highest power outputs of $2.7 \mathrm{~kW}$ each, throughout the boiling tests. Generally, the JOBS when fuelled with $10 \%$ and $20 \%$ Jatropha oil concentrations in the blends, and the NOBS while combusting $10 \%$ Neem oil concentration in the blend recorded shorter Cooking Times in the Controlled Cooking Tests compared to the Butterfly Kerosene Cooking Stove. The results indicated that as the blend ratios of the vegetable oils increased in the kerosene/oil blends, the amount of harmful emissions generated from combustion of these fuel oil blends reduced.
\end{abstract}

Keywords: Biomass, Liquid biofuel, cooking stove, combustion, emissions

\section{Introduction}

Emissions from the combustion of fossil fuels (kerosene and gas), in addition to the felling of trees and use of the by-product wood as fuel for cooking and other heating purposes lead to several problems. These problems include indoor air pollution, which according to Bryden et al. (2005) cause significant health problems for the 2 billion people worldwide that rely on traditional (solid) biomass fuels for their cooking and heating needs. Others are increase in the concentration of Carbon Dioxide $\left(\mathrm{CO}_{2}\right)$ and other Green House Gases (GHGs) in the atmosphere, and global warming due to increase in the global mean temperature. Desertification and drought as consequences of deforestation are also problems resulting from the combustion of fossil and solid biomass fuels.

Smith et al. (2000) pointed out that simple stoves using solid (biomass) fuels do not merely convert carbon into $\mathrm{CO}_{2}$. But because of poor combustion conditions, such stoves actually divert a significant portion of the fuel carbon into Products of Incomplete Combustion (PICs), which in general have greater impacts

${ }^{*}$ Lecturer, Baze University, Nigeria.

${ }^{ \pm}$Professor, Bayero University, Nigeria.

*Professor, Bayero University, Nigeria. 
on climate than $\mathrm{CO}_{2}$. Meanwhile Rehfuess (2006) noted that approximately half of the world's population depend on burning solid fuels for cooking, boiling water and heating. In addition, the World Health Organisation (WHO) estimated that more than 1.5 million people prematurely die each year due to exposure to smoke and other pollutants from burning solid fuels.

Notwithstanding these stark reports on the consequences of burning solid fuels on people and the environment, majority of research studies carried out on cooking stoves have so far been concentrated on the utilisation of solid fuels in improved biomass cooking stoves. Olorunsola (1999) carried out the development and performance evaluation of a briquette-burning stove. The stove, which utilised corn-cob briquettes as fuel material is cylindrical in shape and consisted of three internal compartments namely; combustion chamber, storage chamber and airinlet chamber. Controlled Cooking Test was used to compare the fuel consumption rate and time spent in cooking with the stove and two other cooking stoves (Charcoal and Kerosene Stoves).

Obi et al. (2002) on the other hand, developed and tested the performance of the three burner wood-fired stove. A means of supplying secondary air to the multi-stage wood stove was incorporated, which also had an orifice that can be closed when the stove was not in use. Separate combustion chamber to control the mode of heat generation for even distribution to the cooking grills was also provided in the stove.

Ndirika (2002) also developed and evaluated the performance of charcoal fired cooking stoves. Three different sizes of cooking stoves, which utilised charcoal as source of fuel were designed and fabricated for domestic cooking of food by the rural communities.

The Household Rocket (solid biomass) stove is a well-insulated stove and was developed by Larry Winiarski and Aprovecho Research Center (ARC) of the United States of America (USA). The rocket stove technology has been available for 25 years and it was estimated that half a million rocket stoves might have been in use worldwide (Bryden et al. 2005). Philips prototype (solid biomass) fan stove that incorporated forced-air jets for better mixing of the flame, gases, and air was developed and manufactured by Philips Company of the Netherlands (Philips 2006). Household Karve gasifier (solid biomass) stove that also utilised secondary air, which passes over the top of the combustion chamber was developed by AD Karve of the Appropriate Rural Technology, India (Raj 2007). Berrueta et al. (2008) reported that the Interdisciplinary Group on Appropriate Rural technology (GIRA) and Center for Ecosystems Research (CECO) developed an efficient wood-burning cook stove called the "Patsari", which in Purhepecha language means "the one that keeps", referring to the fact that the device "keeps" (takes care of the users' health, environment and economy). In addition, pieces of charcoal were combusted in bowl-shaped combustion chamber in the Charcoal Jiko stove. Holes allow air to enter the combustion chamber zone from underneath the charcoal. The charcoal Jiko has been disseminated in many African countries (MacCarty et al. 2008).

Furthermore, the Ecostove by Charron (2005) had a chimney and a flat steel plate top for grilling foods or making tortillas. The vented Ecostove had been 
shown to reduce indoor air pollution compared to unvented traditional wood fires. Similarly, ARC developed the World Food Programme (WFP) rocket stove for the United Nations (UN). Metal food containers were used as materials of construction. The combustion chamber was constructed from sheet metal and was surrounded by insulation such as wood ash, pumice or vermiculite. In addition, the Urban Community Development Association (UCODEA) Kampala (Uganda) charcoal stove had a metal body with a ceramic liner and grate to hold the hot charcoal. Two doors on the side near the bottom of the stove can be used to control the amount of air that flows up through the grate to the burning charcoal (Jetter and Kariher 2009).

Meanwhile, several research efforts were carried out on the scientific uses of liquid biofuels and their derivatives in petrol engines, diesel engines, and cooking stoves. The researchers that investigated their utilisation in cooking stoves adapted the existing kerosene cooking stoves in their research efforts. Sahu et al. (2005) investigated the performance and emissions characteristics of Pongamia oil kerosene blends used in commercial kerosene stoves (pressure pump and wick stoves). In addition, Khan et al. (2013) carried out experimental investigation on the effect of using various blends of ethanol and kerosene on the performance of kerosene wick stove. Moreover, Yadav and Jha (2013) carried out a case study on biofuel stove technology, which focused on utilising raw vegetable oil of jatropha seeds as fuel in a modified kerosene cooking stove.

Shanono et al. (2017) carried out the characterisation of neem and jatropha curcas oils with the purpose of obtaining data for the design of the Jatropha Oil Bio Stove (JOBS) and the Neem Oil Bio Stove (NOBS), which were subsequently fuelled with raw vegetable oils - based liquid biofuels. Therefore, this research work was on the performance and emission characteristics of the two liquid biofuels cooking stoves other than the traditional kerosene cooking stove.

It is noteworthy to state that Srivastava and Prasad (2000) much earlier observed that vegetable oils are widely available from a variety of sources, and they are renewable. As far as environmental considerations are concerned, unlike hydrocarbon-based fuels, the sulphur content of vegetable oils is close to zero and hence, the environmental damage caused by sulphuric acid is reduced. Moreover, vegetable oils take away more carbon dioxide from the atmosphere during their production than is added to it by their later combustion. Therefore, it alleviates the increasing carbon dioxide content of the atmosphere. The essence and substance of this observation and the reality of climate change (global warming), whose effect has been manifested on people and the environment, and which is being acerbated by the combustion of solid fuels in cooking stoves, necessitated the design of JOBS and NOBS for the combustion of vegetable oils based fuels for cooking and other domestic heating purposes.

The methodology behind this paper was the establishment of a benchmark from tests carried out with a butterfly kerosene cooking stove. This formed the base metric in determining the performances of the liquid biofuels cooking stoves and the level of emissions generated from their use. The quantitative data collection method was utilised during the tests and the strategies employed were experimentation, observations, and measurements. All the data generated thus 
were numeric and therefore, for each established base metric and the corresponding biofuel stove performance/emission, the quantitative univariate or bivariate comparative descriptive analyses were carried out in the discussion of the results.

\section{Materials and Experimental Methods}

\section{Materials}

The experimental set-up for the WBT and CCT were similar except that in the WBTs, the pot was not covered in all the tests. In addition, the thermometer and emission analyser were not used in the CCTs. The set-up generally consisted of the system, equipment, and emission analyser.

\section{System}

The system includes the butterfly kerosene - cooking stove, and the jatropha oil and neem oil bio stoves as shown in Figure 1. Each of the stoves has its own fuel funnel.

Figure 1. The Kerosene, Jatropha Oil, and Neem Oil Cooking Stoves

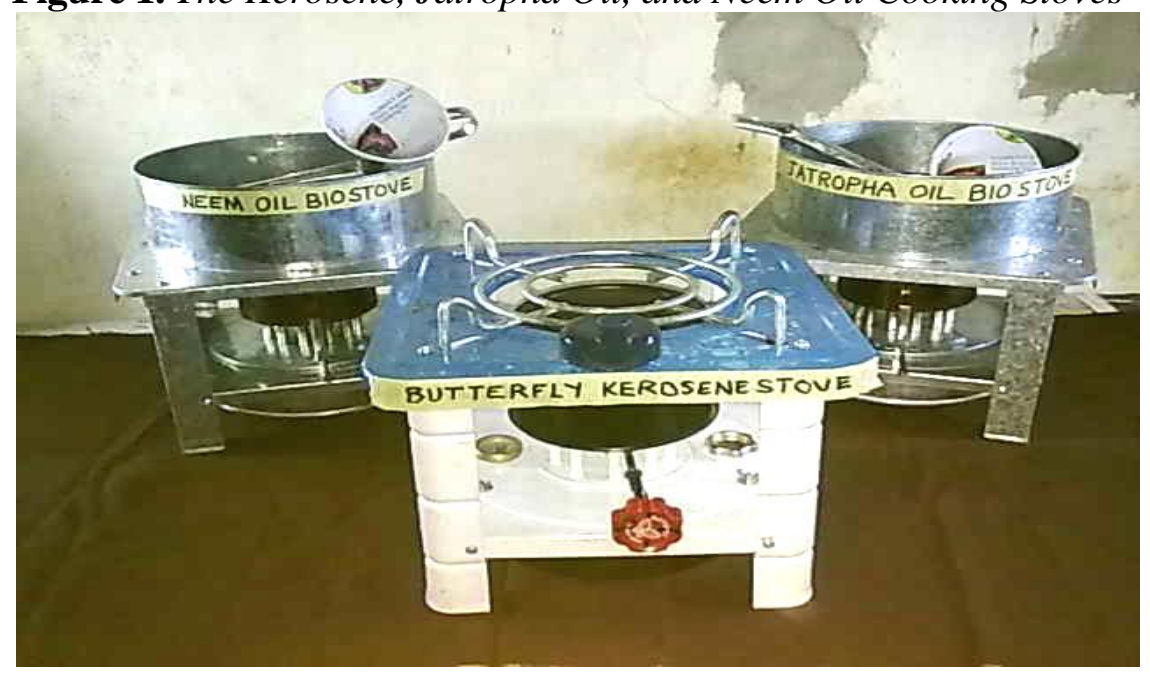

Two cans containing 10 litres of clean water each, and two 6 litres capacity 236-millimetre diameter stainless steel pots with transparent covers were also part of the system as shown in Figure 2. This type of pot was chosen as the standard pot for this work because some of its features were adopted in the design process of the two Bio Stoves (e.g. the design of pots' supports and skirts). Among the types of cooking pots available in the market, it was this type of pot that sat perfectly into the pot supports of the butterfly kerosene stove, whose pot supports dimensions were also adopted in the design of the bio stoves. Meanwhile H.K. Jing Mei Da manufactured the cooking pots, though the country and date of manufacture were not indicated in the pots. When empty, each of the pots has a mass excluding the cover of $1,687.56 \mathrm{~g}$, a mass of $2,239.71 \mathrm{~g}$ with the cover, and a 
total mass of $8,250 \mathrm{~g}$ when filled to the brim with water including the cover. Stainless steel has low thermal diffusivity, which enables the standard pot to have superior heat retention capacity, and thus faster cooking process compared to aluminium cooking pot.

Figure 2. Two 10 litres Water Containers and the Standard Cooking Pots

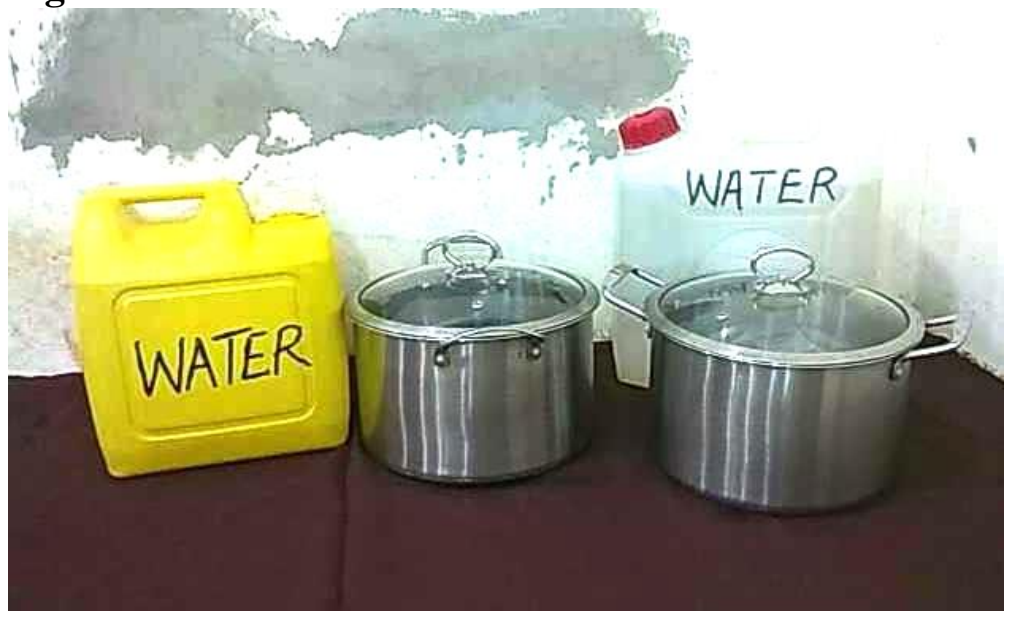

Furthermore, the transparent cover makes the content of the pot visible during cooking. This feature can be appreciated considering that cooking procedure in Nigeria generally commence with boiling water in a pot with the cover in place. Therefore, during a cooking task the cook will know when the water inside the pot starts boiling without necessarily removing the pot's cover. In addition, the state of the food can easily be monitored during the simmering phase of the cooking task.

\section{Equipment}

The equipment used during the tests includes a Technico Graduated Glass Beaker with 2,000 millilitre capacity and a 6,100g capacity Mettler Digital Weighing Equipment.

Figure 3. Equipment Used During the Tests

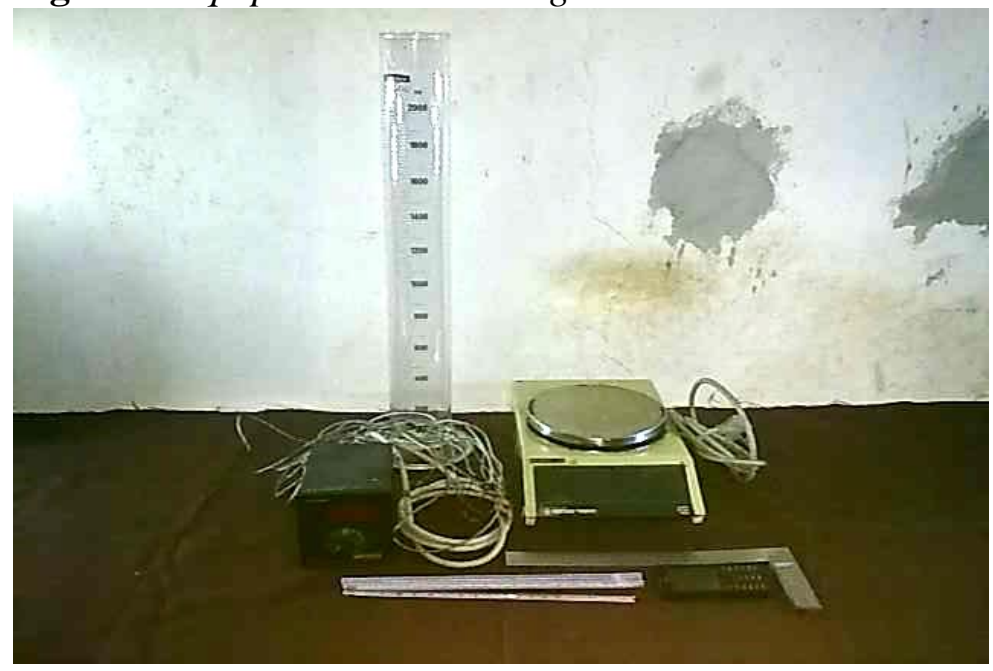


Others are Mercury in Glass Thermometers and ECO 96 IND NEWTRONIC 10-point Digital Indicator (Range Type $\mathrm{K}-50 /+1200^{\circ} \mathrm{C}$ ) with 3 Thermocouples as shown in Figure 3.

Emission Analyser

Gaseous emissions during the WBTs were measured in collaboration with the Nigeria Institute of Transport Technology (NITT), Zaria - Nigeria with a MASTER NHA-506 EN Automotive Emission Analyser. The analyser used Advanced Non-Dispersive Infrared (NDIR) analysis technology to measure the concentrations of unburnt Hydrocarbons (HC), Carbon Monoxide (CO), Carbon Dioxide $\left(\mathrm{CO}_{2}\right)$, and Nitrogen Oxide (NO) during the tests. It has a measuring range of $0-9,999 \mathrm{ppm}(\mathrm{HC}) ; 0-10 \%(\mathrm{CO}) ; 0-18 \%\left(\mathrm{CO}_{2}\right)$, and $0-5,000 \mathrm{ppm}(\mathrm{NO})$. The measurement accuracy is as follows:

HC: $\pm 12 \%$ (abs.) 0 2,000 ppm; $\pm 5 \%$ (rel.) 0 2,000 ppm (whichever is larger); $\pm 10 \%$ (rel.) 2,001 9,999 ppm.

CO: $\pm 0.06 \%$ (abs.); $\pm 5 \%$ (rel.) (whichever is larger).

$\mathrm{CO}_{2}: \pm 0.5 \%$ (abs.); $\pm 5 \%$ (rel.) (whichever is larger).

NO: $\pm 25 \%$ (abs.); $\pm 4 \%$ (rel.) (whichever is larger).

\section{Experimental Methods}

In order to assess and analyse the capability of the Jatropha and Neem Oils Bio Stoves during various cooking tasks, in comparison with the Kerosene Cooking Stove the Water Boiling Test (WBT) version 4.2.3 (as modified) and the Controlled Cooking Test (CCT) version 2.0 were conducted with the stoves. The tests were first conducted with the Butterfly Kerosene Stove in order to obtain data and establish the base metrics for comparison with the performance of the two vegetable oils - based Bio Stoves. Meanwhile, all the tests (WBTs and CCTs) were carried out in a simulated kitchen setting within the Thermo-Fluids laboratory of the Department of Mechanical Engineering, Bayero University Kano-Nigeria, from Monday 16 May to Friday 27 May 2016 (excluding Sunday, a total duration of eleven days).

\section{Water Boiling Test}

The WBT is a simplified simulation of the cooking process. It is intended to measure how efficiently a stove uses fuel to heat water in a cooking pot and the quantity of emissions produced while cooking (GACC 2014). The WBT consist of three phases that immediately follow each other, namely: cold - start high power phase, hot - start high power phase, and the simmer phase. Between each of the three phases, the fuel, water and temperature are weighed by quickly removing the pot and extinguishing the fuel. These measurements of the stove's performance at both high and low (simmer phase) powers help to simulate what is likely to occur when cooking foods that involve boiling and simmering. This type of cooking is believed to be the most common type of cooking (MacCarty et al. 2010). Figure 4 shows the water boiling test setup with kerosene cooking stove. 
Figure 4. Water Boiling Test Setup with Kerosene Cooking Stove

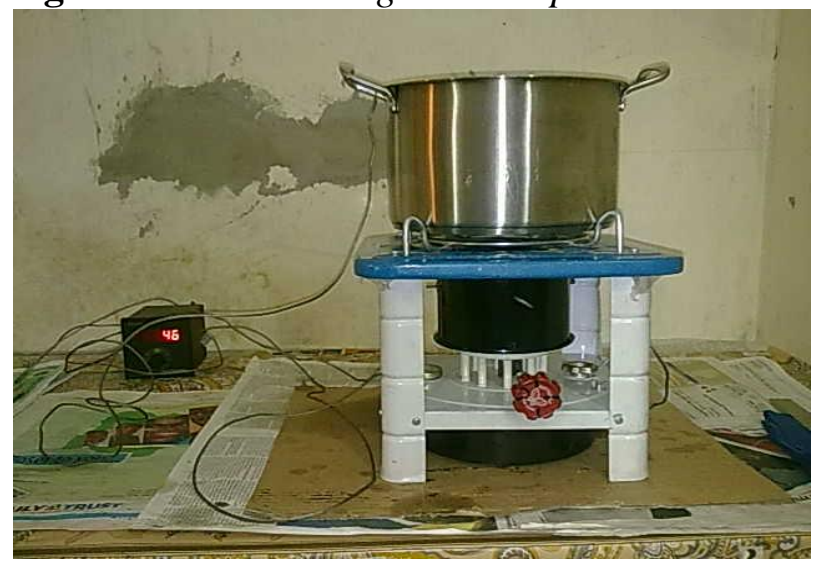

Meanwhile, cold - start means the wicks in the cooking stoves were ignited when the stoves were at room temperature. Hot - start on the other hand was conducted after the first phase or cold - start while the stoves were still hot. There is the need to indicate that there is no specific temperature to denote the hotness of the stoves. Therefore, the word 'hot' is subjective. The temperature of the stove during hot - start must however be above the ambient temperature.

Figure 5. Water Boiling Test Setup with the Biofuel Cooking Stove

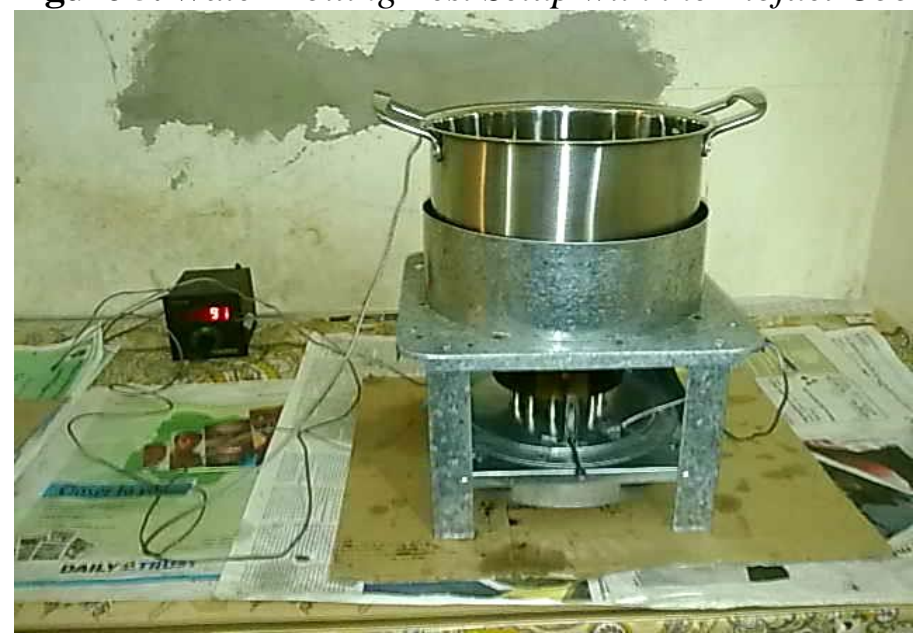

The water boiling test setup with the biofuel cooking stove is shown in Figure 5. Though the WBT version 4.2.3 makes provision for measuring of the quantity of emissions produced while cooking, it was modified in this study to reflect the types of fuels used during the tests as against firewood upon which the WBT protocol was designed. In addition, the simmer phase was omitted since the CCTs in the study were conducted immediately after conducting the two first phases of the WBT in each stove. To facilitate this, two similar pots with the same characteristics were used. Though the capacity of each pot is more than six litres, 3 litres of water was used for each test. As per the WBT protocol, no lids were used on the pots (MacCarty et al. 2010). The key metrics obtained from the WBTs are specific fuel consumption, heat transfer efficiency, cooking stove power and 
emissions generated. The equations for calculating these metrics for both cold-start high-power and hot-start high-power WBTs are similar.

Specific Fuel Consumption (SFC) as defined by the WBT protocol is the fuel required to produce a unit output, whether the output is boiled water, cooked beans, or loaves of bread. (Either for cold-start high-power WBT or hot-start highpower WBT), it is a measure of the amount of fuel/oil required to produce one litre (or kilogram) of boiling water. It is calculated as:

$$
S F C=\frac{m_{f}}{M_{b}} \quad \frac{(\mathrm{kg} \text { fuel })}{(\mathrm{kg} \text { water })}
$$

Where, $\mathrm{m}_{\mathrm{f}}$ is mass of fuel used in $\mathrm{kg}$, and $\mathrm{M}_{\mathrm{b}}$ is mass of water boiled or remaining or mass of cooked food in $\mathrm{kg}$ (Berrueta et al. 2008).

Heat Transfer Efficiency (HTE) is a measure of the fraction of heat produced by the fuel that made it directly to the water in the pot. The remaining energy is lost to the environment (GACC 2014). The equation for calculating HTE is a modified/adapted version of the WBT protocol thermal efficiency equation for wood burning stove and is given as:

$$
\mathrm{HTE}=\frac{4.186 M_{b}\left(T_{f}-T_{i}\right)+2260 M_{v}}{m_{f} \times L C V} \times 100 \%
$$

Where; $\mathrm{M}_{\mathrm{b}}$ is effective mass of water boiled, specific heat of water is 4.186 $\mathrm{J} / \mathrm{g}{ }^{\circ} \mathrm{C}, \mathrm{T}_{\mathrm{f}}$ is final temperature of water, $\mathrm{T}_{\mathrm{i}}$ initial temperature of water, 2260 is the latent heat of evaporation of water in $\mathrm{J} / \mathrm{g}, \mathrm{M}_{\mathrm{v}}$ is mass of water vaporised in grammes, $\mathrm{m}_{\mathrm{f}}$ is the mass of fuel burnt in grammes, and LCV is the lower calorific value of the fuel in $\mathrm{J} / \mathrm{g}$.

The WBT protocol also defines cooking stove power or firepower as a measure of how quickly fuel was burning, and it is reported in Watts (Joules per second). It is a useful measure of the stove's heat output or average power output and is given by;

$$
\mathrm{P}=\frac{m_{f} x L C V}{\left(t_{f}-t_{i}\right) \times 60} \quad(\text { Watts })
$$

where $\left(t_{\mathrm{f}}-\mathrm{t}_{\mathrm{i}}\right)$ is duration of the boiling task in minutes.

In order to facilitate comparison between tests that may have used water with higher or lower initial temperatures, the WBT protocol recommends adjustment of the result (time to boil) to a standard $75^{\circ} \mathrm{C}$ temperature change $\left(25^{\circ} \mathrm{C}\right.$ to $\left.100^{\circ} \mathrm{C}\right)$.

Thus, Temperature Corrected Time to Boil:

$$
\Delta t^{T}=\Delta t \times \frac{75}{T_{f}-T_{i}} \text { mins }
$$

Similarly, temperature corrected specific fuel consumption:

$$
\mathrm{SFC}^{\mathrm{T}}=S F C \times \frac{75}{T_{f}-T_{i}} \mathrm{~kg} \text { fuel/ } k g \text { water }
$$


The emissions produced during the WBTs, which were measured directly, are average values of unburnt $\mathrm{HC}, \mathrm{CO}, \mathrm{CO}_{2}$ and $\mathrm{NO}$.

\section{Controlled Cooking Test}

The Controlled Cooking Test (CCT) is designed to assess the performance of the improved (new/newly designed) stove relative to the common or traditional stoves that the improved (new) model is meant to replace. Stoves are compared as they perform a standard cooking task that is closer to the actual cooking that local people do every day (Bailis et al. 2004). The CCTs were conducted with the three stoves (kerosene stove, jatropha oil bio stove, and the neem oil bio stove) immediately after the WBTs were completed. This necessitated omission of the simmer phase in the WBTs as earlier stated.

The proprietress of Gaskiya Restaurant was contracted to prepare and cook eight plates of Jollof rice with each of the cooking stove with the appropriate test fuel. Gaskiya Restaurant is a private food, snacks and drinks eatery joint that serve students, academic staff and non-academic staff of the main (new) campus, Bayero University Kano - Nigeria. It is located in the students' mini-market within the University community, and the proprietress was very much conversant with the butterfly kerosene stove. However, in line with the CCT version 2.0 testing procedure as outlined in (GACC 2004), her knowledge on its basic operation was confirmed few days prior to commencement of the tests.

Subsequently, the operation of the two newly designed and fabricated bio stoves were demonstrated to her. She then had a hands-on experience on the stoves. The two components of the Bio Stoves that amazed her are the wick pipes control system (which is a lever mechanism as against the rack and pinion in the kerosene stove), and the pot skirt. The only training per se, was the requirement that whenever the cooking task begins, she should place the cooking pot concentrically within the pot skirt in order to maintain uniform clearance from the pot to the skirt all-round the pot skirt.

The same quantity of rice $(1,000 \mathrm{~g})$ and condiments $(350 \mathrm{~g})$ were cooked during each cooking task. This quantity of rice when done was enough to be served to eight grown up persons, each in an expanded polystyrene take away plate. Meanwhile fried pieces of chicken and the salad, which were prepared separately and does not form part of the CCT calculation were served with the rice. The objective measure of "when the meal is done" was left for the cook to indicate since she had been in the restaurant business for over twenty-years. In each cooking task therefore, she simply indicates that "the meal is done" and the time was recorded. The CCT cooking task concluding procedure was then followed accordingly. Figure 6 shows the cooking in progress. 
Figure 6. The Controlled Cooking in Progress

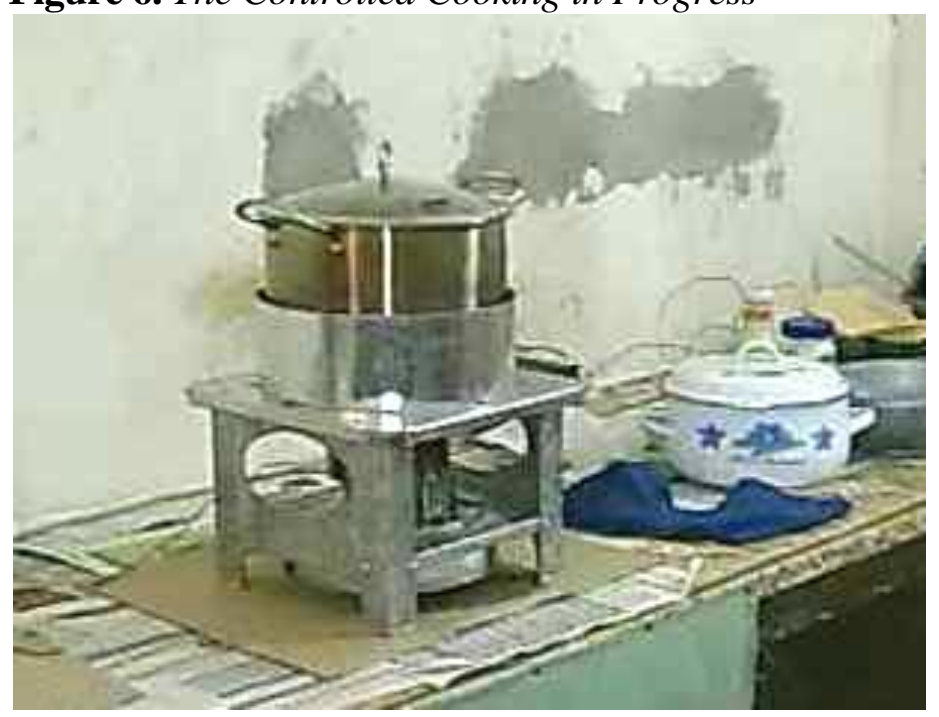

The CCT version 2.0 states that specific fuel consumption is the principal indicator of stove performance for the CCT. It tells the tester the quantity of fuel required to cook a given amount of food for the standard cooking task. It is calculated as a simple ratio of fuel to food;

$$
\begin{aligned}
S F C & =\frac{\text { mass of fuel consummed in grammes }}{\text { mass of cooked food in kilogrammes }} \\
S F C & =\frac{m_{f}}{M_{f_{d}}} \times 1000 \mathrm{~g} \text { fuel } / \mathrm{kg} \text { cooked food }
\end{aligned}
$$

$\mathrm{m}_{\mathrm{f}}$ is the mass of fuel consumed during the cooking task, and $\mathrm{M}_{\mathrm{fd}}$ is the mass of food cooked (GACC 2004).

Total Cooking Time $(\Delta \mathrm{t})$ is also an important indicator of stove performance in the CCT protocol. Depending on local conditions and individual preferences, stove users may value this indicator more or less than the fuel consumption indicator (Bailis et al. 2004). This is very true as correlated by the proprietress of Gaskiya Restaurant. She stated that; "irrespective of the quantity of food to be prepared and the amount of fuel to be consumed during a cooking task, a stove that enables me to complete the task in the shortest possible time is what I desire. This is because during peak hours of my business (1,300 hours to 1,500 hours), my customers expect me to serve their meals immediately after placing an order".

Thus a student or lecturer just out from the lecture hall feeling very tired and hungry, would not take it kindly if told to wait for some time before he/she is served a meal, because the food is not yet ready.

Figure 7 shows salad cream being added to the food, while in Figure 8 the food was ready to be served. 
Figure 7. Salad Cream Being Added to the Cooked Food

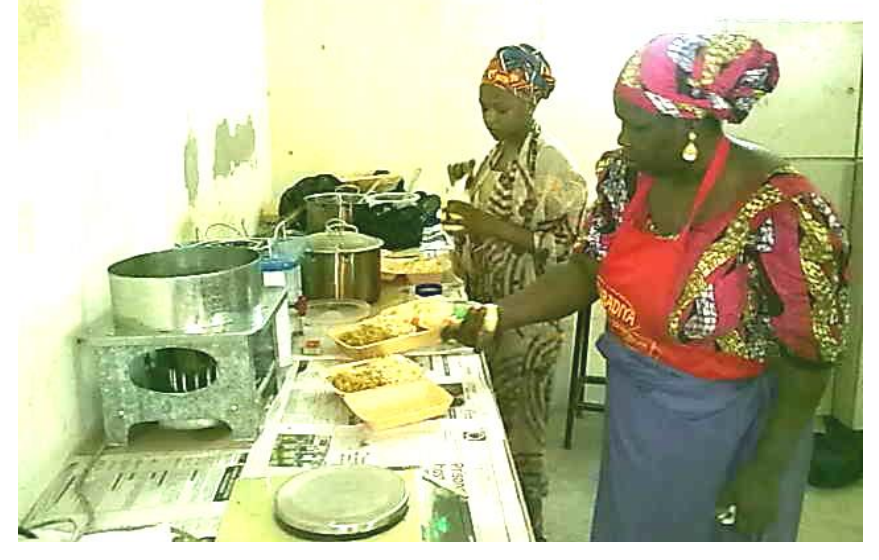

The total cooking time was calculated as a simple clock difference:

$$
\Delta \mathrm{t}=\mathrm{t}_{\mathrm{f}}-\mathrm{t}_{\mathrm{i}}
$$

where $t_{i}$ and $t_{f}$ are the initial/start and final/finish times of cooking in minutes.

Figure 8. Food Ready to be served

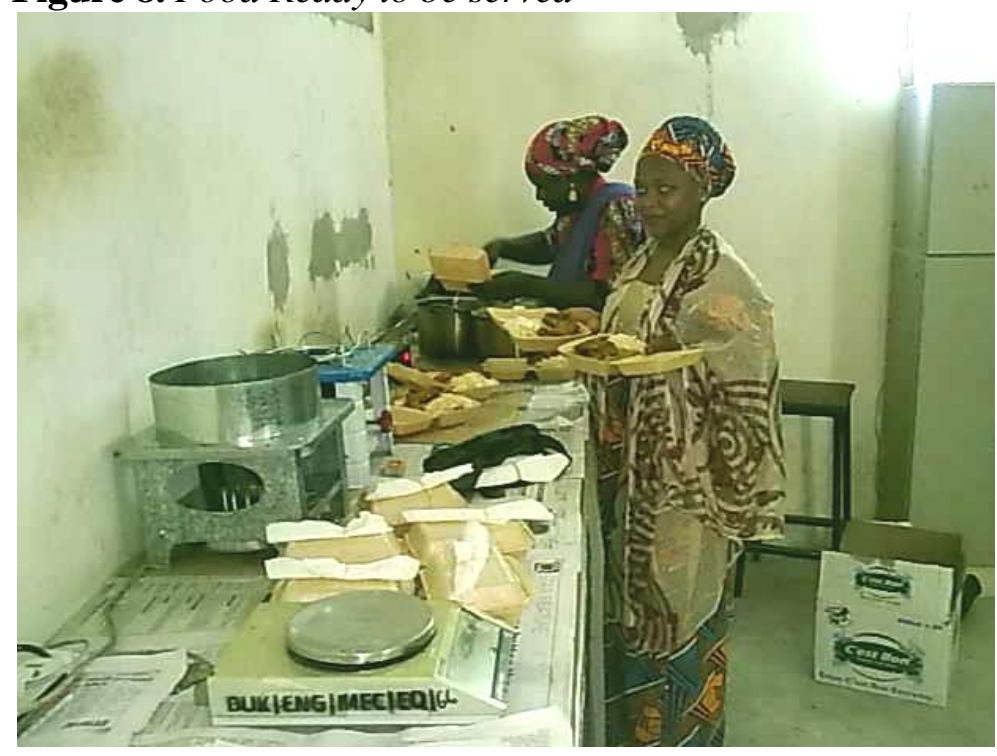

\section{Results and Discussion}

For convenience, abbreviations of names of the stoves were mostly used in discussion of the results. Accordingly, BFS denote the Butterfly Cooking Stove, JOBS represents the Jatropha Oil Bio Stove, and NOBS indicates Neem Oil Bio Stove. 
Water Boiling Tests

Figure 9. Temperature Corrected Specific Fuel Consumption of the BFS, JOBS, and NOBS during the High Power, Cold-Start Water Boiling Tests

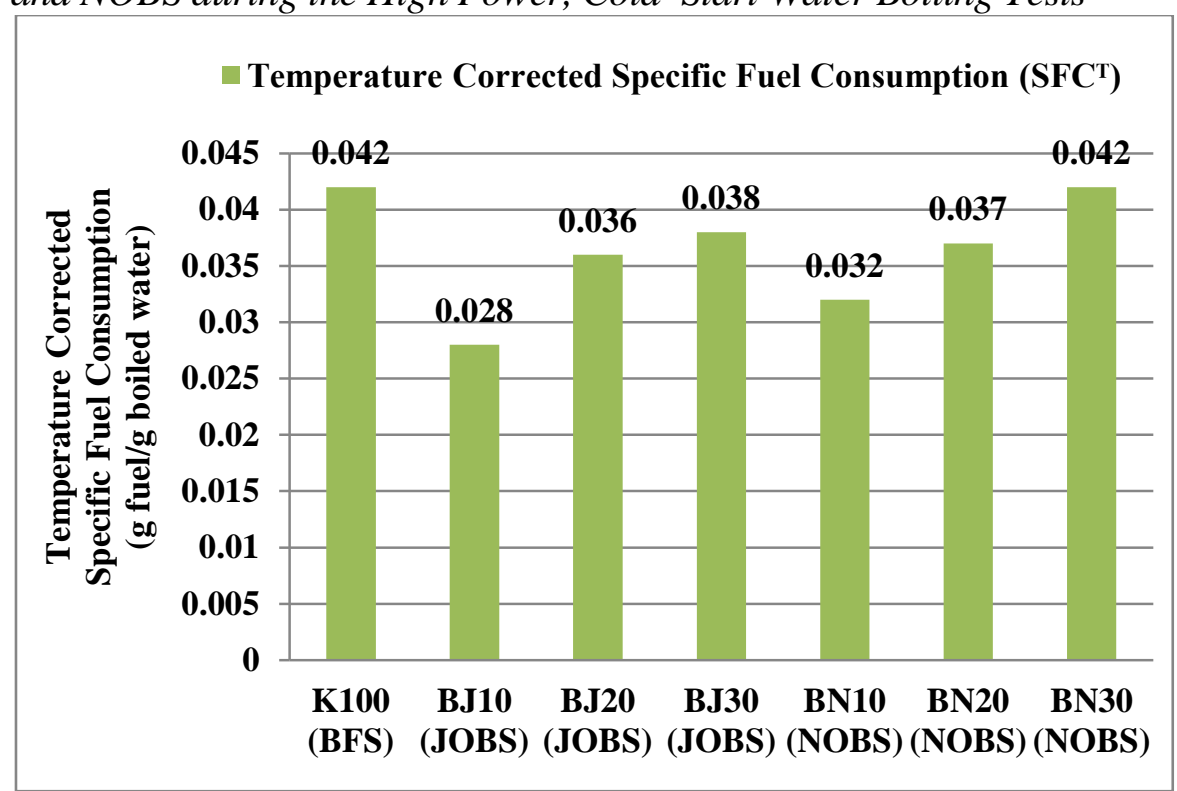

Figure 10. Temperature Corrected Specific Fuel Consumption of the BFS, JOBS, and NOBS during the High Power, Hot-Start Water Boiling Tests

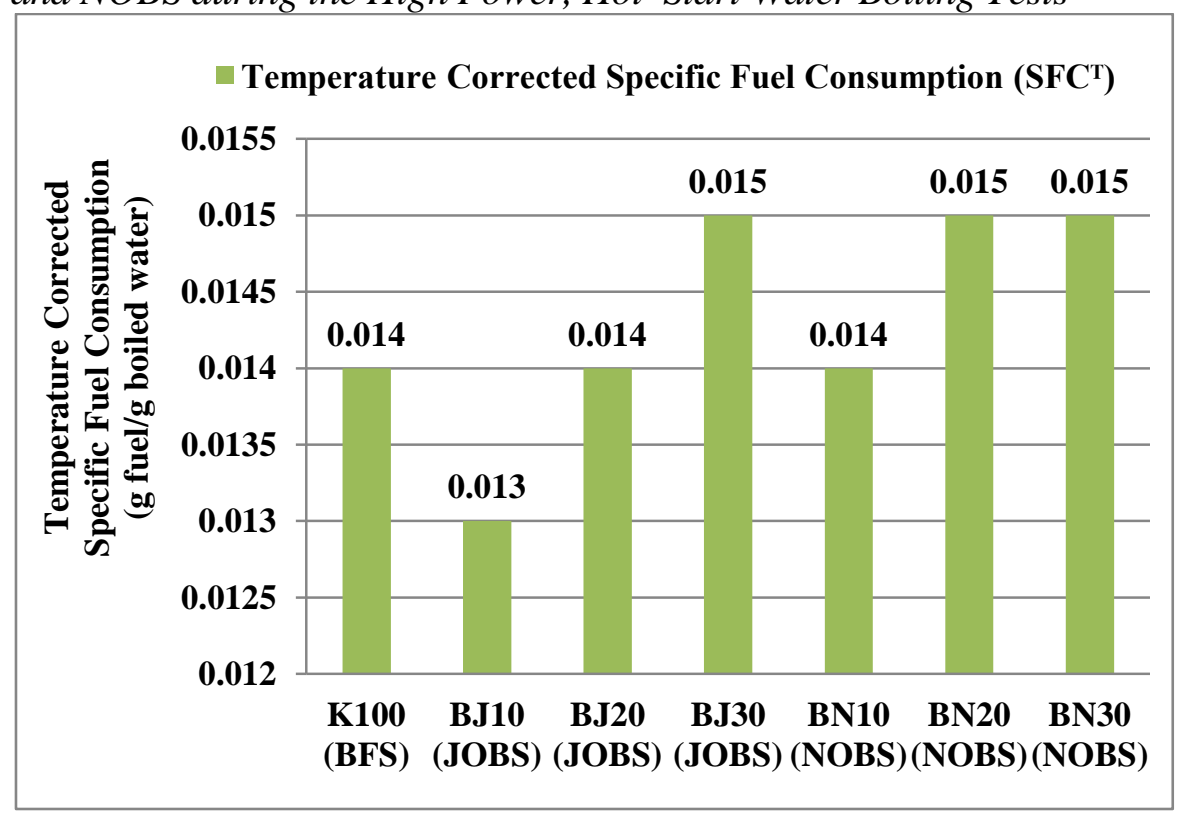

Figure 9 shows comparison of the temperature corrected specific fuel consumption of the Butterfly Kerosene Stove and the Bio Stoves when tested with the corresponding fuel/fuel oil blends during the High Power Cold-Start Water Boiling Tests. The Temperature Corrected Specific Fuel Consumption $\left(\mathrm{SFC}^{\mathrm{T}}\right)$ recorded for the BFS was $0.042 \mathrm{~g}$ fuel/g boiled water, the NOBS while combusting BN30 consumed similar amount of $\mathrm{g}$ fuel/g boiled water. The two bio stoves 
consumed fewer amounts of $\mathrm{BJ} 10, \mathrm{BJ} 20, \mathrm{BJ} 30, \mathrm{BN} 10$, and $\mathrm{BN} 20$ fuel oil blends, with JOBS being the least consumer while combusting BJ10 fuel oil blend $(0.028$ $\mathrm{g}$ fuel/g boiled water) compared to the BFS.

Figure 10 meanwhile represent values of the temperature corrected specific fuel consumption of the stoves during the High Power Hot-Start Water Boiling Tests. In these tests, similar amount of $\mathrm{SFC}^{\mathrm{T}}(0.014 \mathrm{~g}$ fuel $/ \mathrm{g}$ boiled water) was recorded for the JOBS (BJ20), NOBS (BN10), and the BFS (K100). However, the two bio stoves (JOBS and NOBS) proved to be the highest fuel consumers $(0.015)$ while combusting BJ30, BN20, and BN30. Meanwhile, the JOBS (BJ10) had the least $\mathrm{SFC}^{\mathrm{T}}$ (0.013 $\mathrm{g}$ fuel/g boiled water) when compared with the base metric.

Figures 11 and 12 indicate comparison of the heat transfer efficiencies of the BFS, JOBS and NOBS when tested with the respective fuel/fuel oil blends in the cold start and hot start water boiling tests respectively.

Figure 11. Heat Transfer Efficiencies of the BFS, JOBS, and NOBS in the High Power, Cold-Start Water Boiling Tests

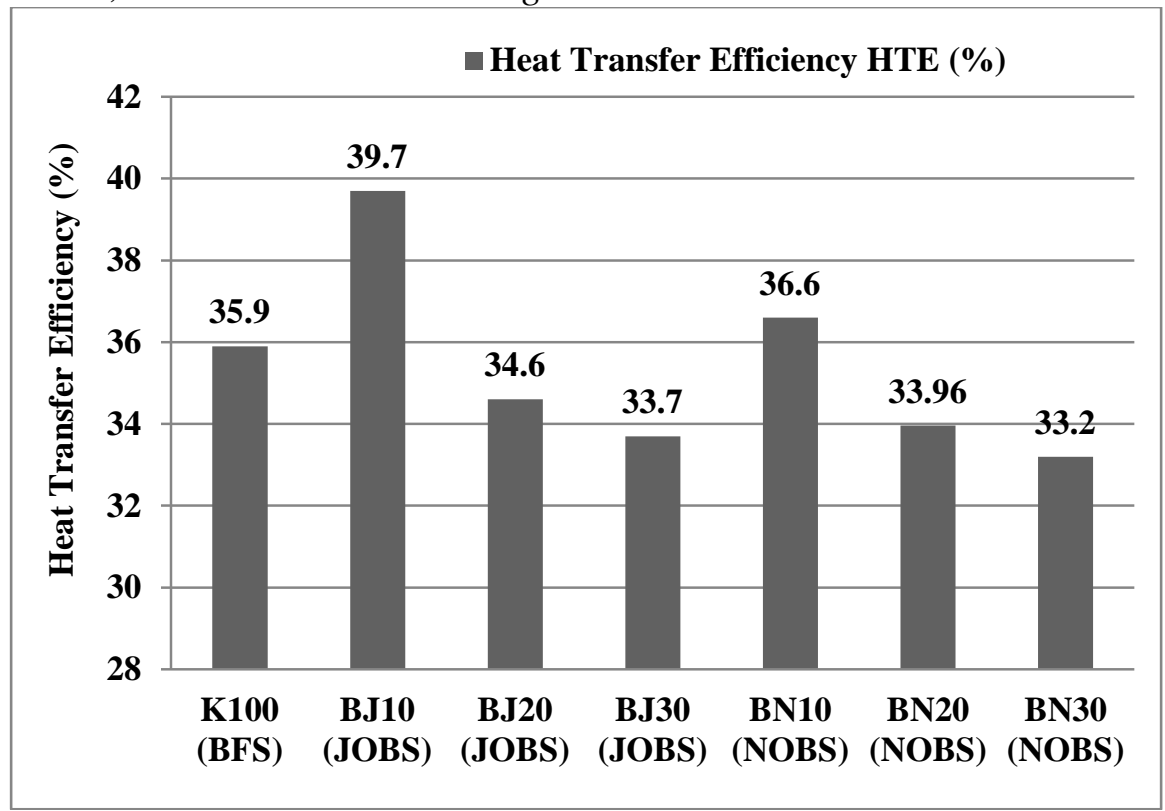

The Heat Transfer Efficiency (HTE) of BFS during the tests was 35.9\%, the four fuel oil blends (BJ20, BJ30, BN20, and BN30) each produced lower values of HTEs $(34.6 \%, 33.7 \%, 33.96 \%$, and $33.2 \%$ respectively) than the base metric. However, the JOBS (BJ10) had the highest HTE of 39.7\%, which was followed by the NOBS (36.6\%) while combusting BN10 fuel oil blend.

In the hot-start boiling tasks, the BFS had the least HTE of $66.13 \%$ compared to the two bio stoves. The JOBS when tested with BJ10 fuel oil blend had the highest HTE of $69.92 \%$, while BN10, BJ20, BJ30, BN20, and BN30 each produced $69.45 \%, 68.36 \%, 68.22 \%, 68.2 \%$, and $68 \%$ when combusted in the NOBS, JOBS, JOBS, NOBS, and NOBS respectively. 
Figure 12. Heat Transfer Efficiencies of the BFS, JOBS, and NOBS in the High Power, Hot - Start Water Boiling Tests

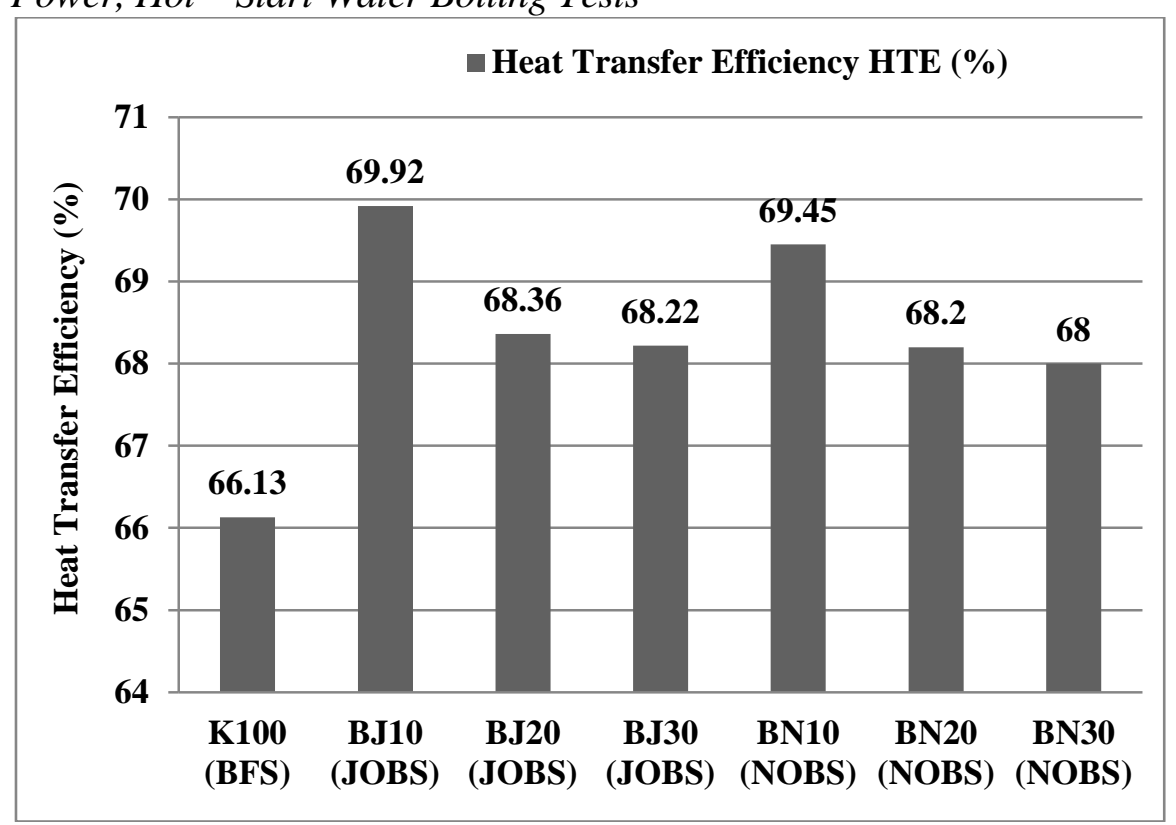

These results indicated that based on heat transfer efficiency considerations, the Bio stoves were better suited for hot start water boiling tasks with the six fuel oil blends as fuels and were more efficient than the Butterfly Kerosene - Cooking stove in the hot start boiling operation.

Generally, all the three stoves recorded higher heat transfer efficiencies in the hot start than in the cold start boiling tests. Moreover, the high thermal conductivities and heat capacities of the fuel oil blends, in addition to the pot skirts, could have contributed to the higher heat transfer efficiencies of the Bio stoves compared to the Butterfly stove, in spite of their lower heating values than the kerosene fuel as enunciated by Shanono et al. (2017).

Figures 13 shows the comparisons of the values of firepower for the cooking stoves at cold-start water boiling tests. The combustion of two fuel oil blends (BJ10 and BJ20) in these tests, produced $2.7 \mathrm{~kW}$ firepower from the JOBS bio stove at different times. This firepower was equivalent to that produced from the combustion of $\mathrm{K} 100$ in the BFS. Meanwhile, more than $2.2 \mathrm{~kW}$ average power output each, was produced from combustion of the remaining fuel oil blends; the least being $2.1 \mathrm{~kW}$, which was obtained from combustion of BN30 in the NOBS.

There was significant drop in the firepower produced from the base metric (BFS) from $2.7 \mathrm{~kW}$ in the cold-start to $1.95 \mathrm{~kW}$ in the hot-start tests. Three fuel oil blends produced more than this value from their combustion; $2.1 \mathrm{~kW}$ (BJ10), $2.19 \mathrm{~kW}$ (BJ20), and $1.97 \mathrm{~kW}$ (BN10) in the corresponding bio stoves. Similarly, the combustion of the other three fuel oil blends produced firepower values of 1.9 $\mathrm{kW}$ (BJ30), $1.87 \mathrm{~kW}$ (BN20), and $1.94 \mathrm{~kW}$ (BN30) in their respective stoves, which were lower than that produced from combustion of the base metric in the BFS. 
Figure 13. Firepower of the BFS, JOBS, and NOBS in the High Power, ColdStart Water Boiling Test

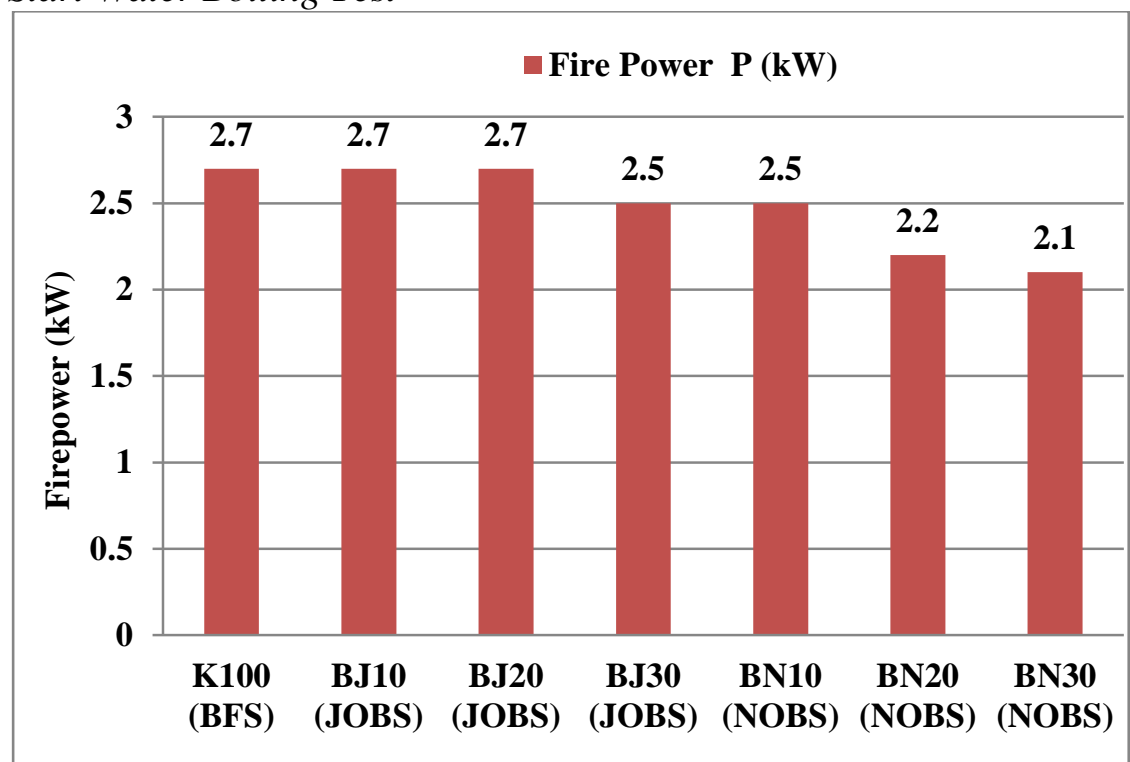

Figure 14. Firepower of the BFS, JOBS, and NOBS in the High Power, Hot-Start Water Boiling Tests

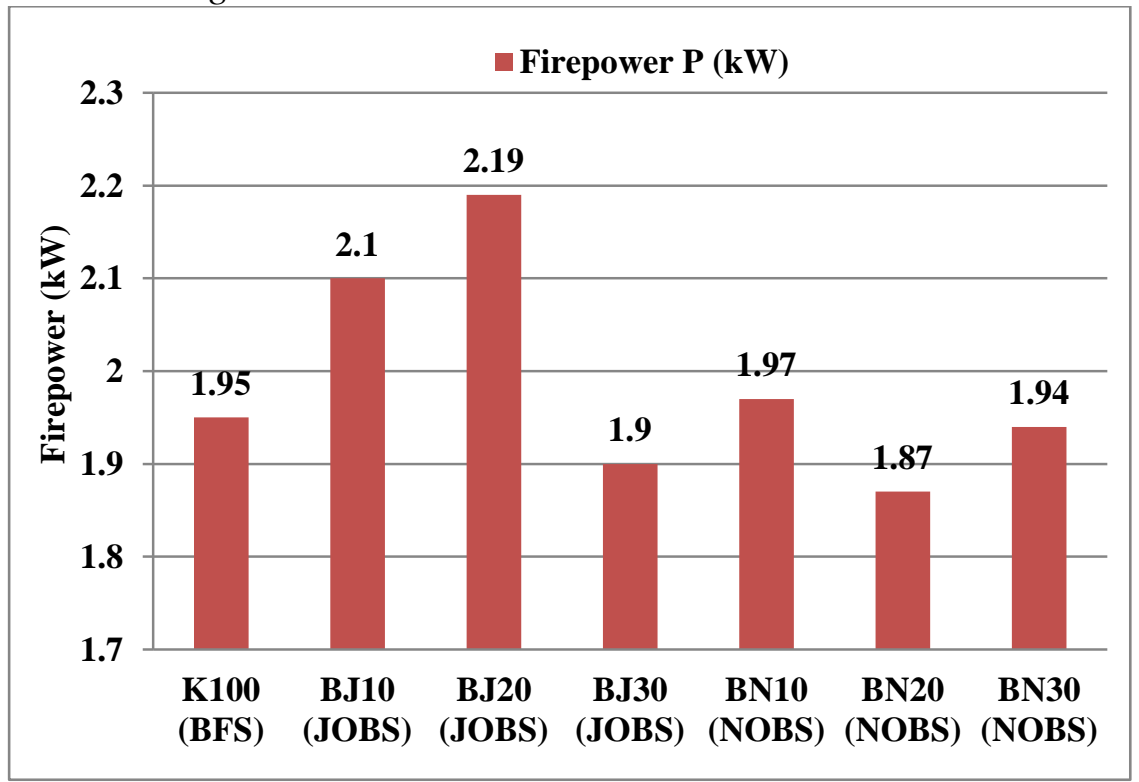

\section{Controlled Cooking Tests}

Figure 15 represents values of the Specific Fuel Consumption (SFC) and the total cooking time indicators for the three stoves studied, which were tested with the respective fuel/fuel oil blends in the controlled cooking performance tests. The base metric, while combusting kerosene consumed $47.1 \mathrm{~g}$ fuel $/ \mathrm{kg}$ cooked food in 36 seconds. The NOBS (BN20) had similar performance characteristics with the BFS. 
Meanwhile, the JOBS was recorded to have both the least SFC of $43.37 \mathrm{~g}$ fuel/kg cooked food and total cooking time of 30 seconds when utilised with the BJ10 fuel oil blends. The next stove with least values was the same JOBS with BJ20 as fuel (44.19 $\mathrm{g}$ fuel/ $\mathrm{kg}$ cooked food in 33 seconds), and then NOBS while combusting BN10 fuel oil blend (46.17 $\mathrm{g}$ fuel $/ \mathrm{kg}$ cooked food in 34 seconds). The NOBS as always has the highest specific fuel consumption and longer cooking time when fuelled with the BN30 fuel oil blend ( $48.75 \mathrm{~g}$ fuel $/ \mathrm{kg}$ cooked food in 39 seconds).

Generally, the JOBS when fuelled with BJ10 and BJ20 fuel oil blends, and the NOBS fuelled with BN10 had superior performance characteristics (least fuel consumption and shorter cooking time) than the Butterfly kerosene - cooking stove in the CCT. It is worth mentioning that the performances of the three cooking stoves in the Controlled Cooking Tests were similar to their Temperature Corrected Specific Fuel Consumption performances in the Water Boiling Tests, if both the Cold - Starts and Hot - Starts were considered.

Figure 15. Specific Fuel Consumption and Total Cooking Time of the BFS, JOBS, and NOBS during the Controlled Cooking Tests

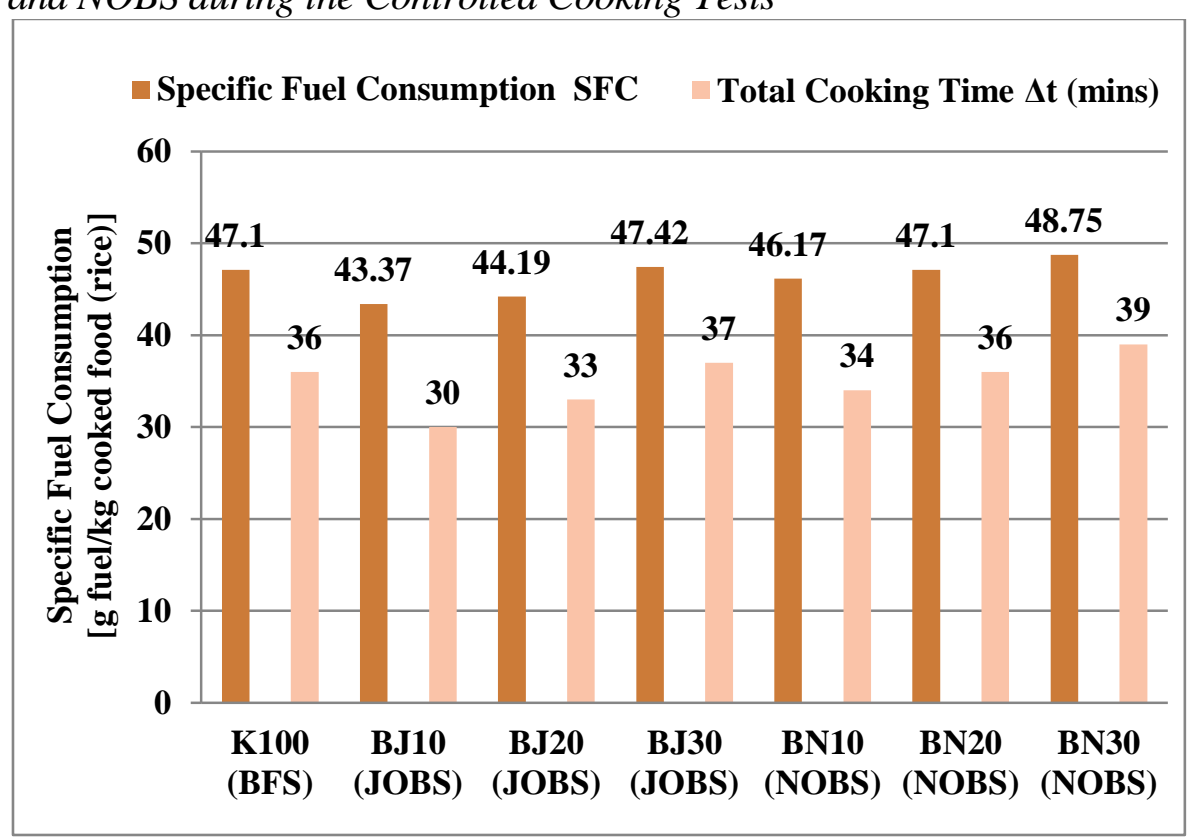

Emissions

The emissions analysed were the average values of unburnt Hydrocarbons (HC), Nitrogen Oxide (NO), Carbon Dioxide $\left(\mathrm{CO}_{2}\right)$, and Carbon Monoxide (CO) produced during the Water Boiling Tests.

Figure 16 shows the average values of $\mathrm{HC}$ and $\mathrm{NO}$ emissions obtained from boiling 2.5 litres of water with the butterfly stove and the bio stoves. The JOBS fuelled with BJ10 fuel oil blend recorded the highest level of unburnt hydrocarbons emission of $24 \mathrm{ppm} \mathrm{HC}$ and $1 \mathrm{ppm}$ NO. This was followed by the base metric (BFS) with 14 ppm HC and 1 ppm NO, and the NOBS (BN10) with 14 ppm HC 
and 5 ppm NO. Meanwhile the JOBS when fuelled with BJ20 and BJ30 produced the cleanest emissions of $0 \mathrm{ppm} \mathrm{HC}$ and $0 \mathrm{ppm} \mathrm{NO}$ each. The next cleanest emission of $1 \mathrm{ppm} \mathrm{HC}$ and $0 \mathrm{ppm}$ NO was produced by the NOBS while combusting the BN30 fuel oil.

Figure 16. Concentration of Unburnt Hydrocarbons and Nitrogen Oxide, Emitted from the BFS, JOBS, and NOBS during the WBTs

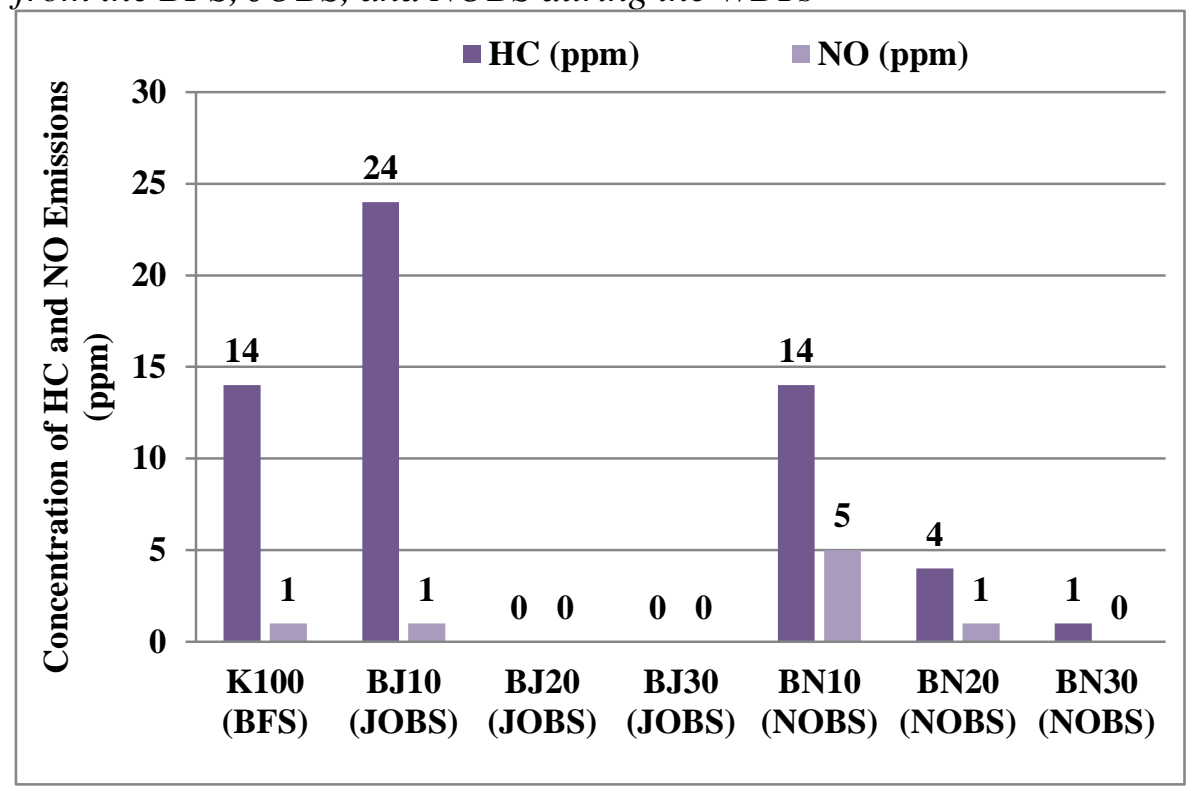

Figure 17. Concentration of Carbon Monoxide and Carbon Dioxide emitted from the BFS, JOBS, and NOBS during the WTBS

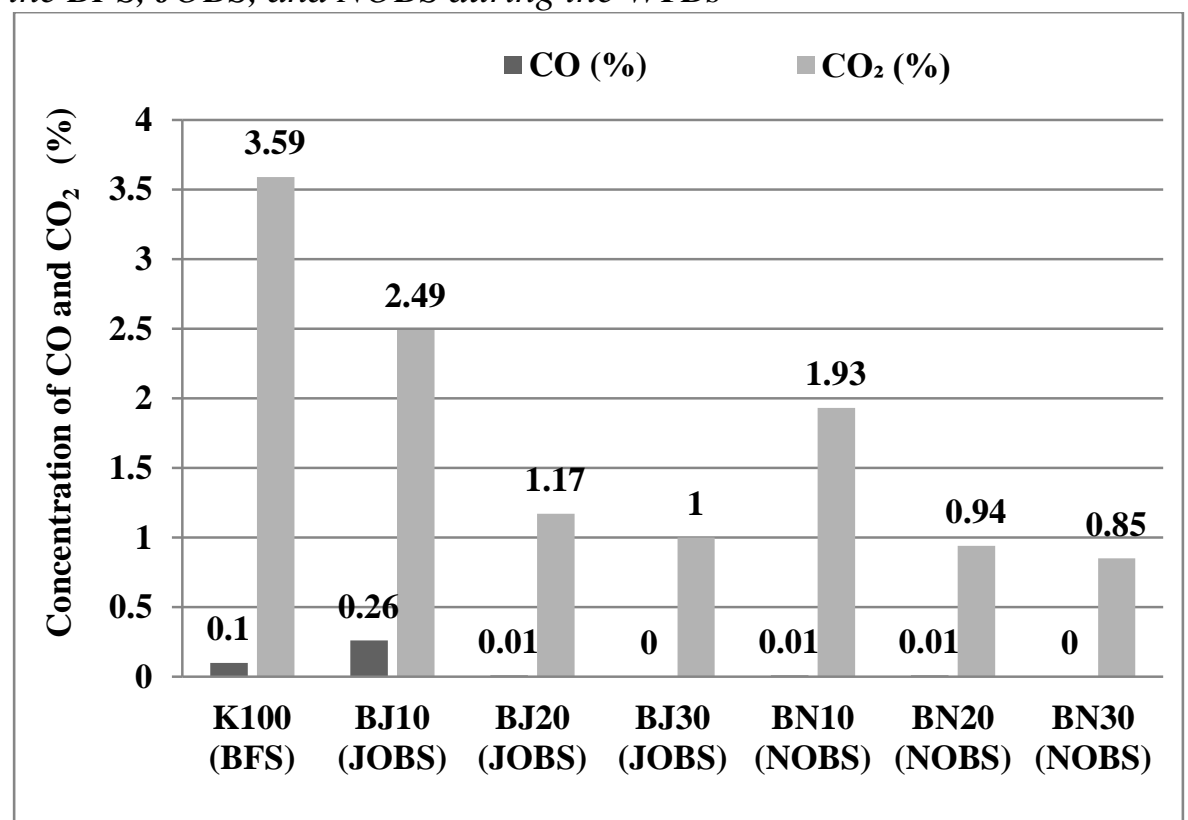

Figure 17 on the other hand indicates the average values of $\mathrm{CO}_{2}$ and $\mathrm{CO}$ emissions produced during the same performance task as in figure 16. The base 
metric was recorded to have the highest $\mathrm{CO}_{2}$ emission level of $3.59 \%$ while combusting kerosene, this was followed by the JOBS (BJ10) with $2.49 \%$. The two stoves swapped positions on CO emissions with the JOBS (BJ10) emitting 0.26\% and the BFS (K100) producing $0.1 \%$.

The emissions of unburnt hydrocarbons indicate incomplete combustion and the vapours can be harmful if inhaled. The 100-year Global Warming Potential (GWP) of $\mathrm{HC}$ is approximately 12 times that of $\mathrm{CO}_{2}$ (Edwards and Smith 2002). Nitrogen oxide is an ozone precursor and when dissolved in atmospheric moisture can result to acid rain. It is (believed) to be greenhouse neutral and as such, the Intergovernmental Panel on Climate Change (IPCC) does not present a GWP for it (MacCarty et al 2008, Forster and Ramaswamy 2007). CO is one of the primary products of incomplete combustion. It has a GWP of 1.9 times that of $\mathrm{CO}_{2}$ and is a large contributor to the localised air pollution in urban areas (MacCarty et al. 2008).

It can be asserted from the GWP ratings of especially $\mathrm{HC}$ and $\mathrm{CO}$ in relation to $\mathrm{CO}_{2}$ as outlined above, and the analyses of results of the emissions generated by the three stoves tested, that the cleanest and less harmful fuel/fuel oil blend when combusted in the respective cooking stove was the BJ30 fuel oil blend. This was followed in consecutive order by; BN30, BJ20, and BN20. The culprits were BJ10, BFS, and BN10. Analyses of the results also indicated that as the blend ratios of the vegetable oils increased in the kerosene/oil blends, the amount of harmful emissions generated from combustion of these fuel oil blends reduced.

\section{Conclusions}

The combustion of fossil and solid biomass fuels in cooking stoves lead to indoor air pollution, and the concentration of carbon dioxide and other products of incomplete combustion in the atmosphere. Others are global warming, and desertification and drought as consequences of deforestation.

The utilisation of vegetable oils and their derivatives as fuels in liquid biofuels cooking stoves could significantly reduce the aforementioned problems. This manifested in the performance tests carried out on the Jatropha Oil Bio Stove and the Neem Oil Bio Stove in comparison with the performance of the Butterfly Kerosene Cooking Stove.

The results indicated that based on heat transfer efficiency considerations, the Bio stoves were better suited for hot start water boiling tasks with the six fuel oil blends as fuels and were more efficient than the Butterfly Kerosene - Cooking stove in the hot start boiling operation. Generally, all the three stoves recorded higher heat transfer efficiencies in the hot start than in the cold start boiling tests.

It can be asserted from the GWP ratings of especially $\mathrm{HC}$ and $\mathrm{CO}$ in relation to $\mathrm{CO}_{2}$ and the analyses of results of the emissions generated by the three stoves tested, that the two Bio Stoves, JOBS and NOBS, produced the cleanest and less harmful emissions than the BFS during the water boiling tests. The results also indicated that as the blend ratios of the vegetable oils increased in the kerosene/oil 
blends, the amount of harmful emissions generated from combustion of these fuel oil blends reduced.

\section{Recommendations}

It is recommended that further research studies should be carried out on the following:

i. The utilisation of bio ethanol/jatropha oil blends as fuels in the Bio Stoves for cooking purposes.

ii. The utilisation of bio ethanol/neem oil blends as fuels in the Bio Stoves for cooking purposes.

\section{References}

Bailis R, Ogle D, Still D, Smith KR, Edward R (2004) The water boiling test version 1.5. Berkeley, California: University of California-Berkeley.

Berrueta VM, Edwards RD, Masera OR (2008) Energy performance of wood-burning cook stoves in Michoacan, Mexico. Renewable Energy 33(5): 859-870.

Bryden, M., Still, D., Scott, P., Hoffa, G., Ogle, D., Bailis, R. and Goyer, K. (2005). Design Principles for Wood Burning Cook Stoves, Aprovecho Research Center/Shell Foundation/Partnership for Clean Indoor Air, USEPA EPA-402 - K - 05_004.

Charron D (2005) The ecostove - getting rid of nearly $90 \%$ of kitchen wood smoke. Boiling Point 50:1-41.

Edwards RD, Smith KR (2002) Carbon balances, global warming commitments and health implications of avoidable emissions from residential energy use in China; evidence from an emissions database. Presented at the Air Pollution as a Climate Forcing: A Workshop.

Forster P, Ramaswamy V (2007) Changes in atmospheric constituents and in radiative forcing. Retrieved from: https://bit.ly/31ARkHO.

GACC (2004) Controlled cooking test version 2.0. Retrieved from: http://cleanstoves.org/ technology _and fuels/testing/protocols.html. [Accessed 6 June 2016].

GACC (2014) The water boiling test version 4.2.3: cook stove emissions and efficiency in a controlled laboratory setting. Retrieved from: https://www.cleancookingalliance. org/binary-data/DOCUMENT/file/000/000/399-1.pdf. [Accessed 7 June 2016].

Jetter JJ, Kariher P (2009) Solid-fuel household cook stoves: characterization of performance and emissions. Biomass and Bio Energy 33(2): 294-305.

Khan MY, Khan FA, Beg MS (2013) Ethanol-kerosene blends: fuel option for kerosene wick stove. International Journal of Engineering Research and Applications 3(1): 464-466.

MacCarty N, Ogle D, Still D, Bond T, Roden C (2008) A laboratory comparison of the global warming impact of five major types of biomass cooking stoves. Energy for Sustainable Development XII(2): 56-65.

MacCarty N, Still D, Ogle D (2010) Fuel use and emissions performance of fifty cooking stoves in the laboratory and related benchmarks of performance. Energy for Sustainable Development 14(3): 161-171. 
Ndirika VIO (2002) Development and performance evaluation of charcoal-fired cooking stoves. Nigerian Journal of Renewable Energy 10(1\&2): 71-77.

Obi AI, Yawas DS, Dauda M (2002) Development and test performance of a three-burner wood-fired stove. Nigerian Journal of Renewable Energy 10(1 \& 2): 63-70.

Olorunisola AO (1999) The development and performance evaluation of a briquette burning stove. Nigerian Journal of Renewable Energy 7(1 \& 2): 91-95.

Philips (2006) Philips develops a woodstove that saves live and preserves energy resources. Philips Research Press Release. Retrieved from: https://www.betuco.be/ stoves/Woodstove\%20Philips.pdf.

Raj NG (2007) Seeking to make fire without smoke. The Hindu, Chennai - India, June 28.

Rehfuess E, World Health Organization (2006). Fuel for life: household energy and health. World Health Organization. Retrieved from: https://apps.who.int/iris/handle/ 10665/43421.

Sahu D, Shetty D, Kumar R, Bekal S (2005) Performance and emission characteristics of pongamia oil-kerosene blend used in commercial kerosene stove. Energy and Power 5(1A): 19-27.

Shanono A, Diso I, Garba I (2017) Characterisation of neem and jatropha curcas oils and their blends with kerosene for combustion in liquid biofuels cooking stoves. Journal of Technology Innovations in Renewable Energy 6(2): 55-65.

Smith KR, Umar R, Kishore VVN, Zhang J, Joshi V, Khalil MAK (2000) Greenhouse implications of household stoves: an analysis of India. Annual Review of Energy and the Environment 25(1): 741-763.

Srivastava, A. and Prasad, R. (2000). Triglycerides-based Diesel Fuels. Renewable and Sustainable Energy Reviews 4: 111-133.

Yadav A, Jha PC (2013) A case study on biofuel stove technology: jatropha as a biofuel. International Journal of Technology Enhancement and Emerging Engineering Research 1(2): 14-18. 